\title{
Defining asthma in children: how well do parents, doctors and spirometry agree?
}

\author{
Koos Korsten ${ }^{1}$, Christiana A. Naaktgeboren ${ }^{2}$, Louis J. Bont ${ }^{1}$, \\ Cornelis K. van der Ent ${ }^{3}$ and Marieke L.A. de $\mathrm{Hoog}^{2}$
}

Affiliations: ${ }^{2}$ Dept of Paediatric Infectious Diseases and Immunology, Wilhelmina Children's Hospital University Medical Centre Utrecht, Utrecht, The Netherlands. ${ }^{2}$ Julius Centre for Health Sciences and Primary Care, University Medical Centre Utrecht, Utrecht, The Netherlands. ${ }^{3}$ Dept of Paediatric Pulmonology, Wilhelmina Children's Hospital, University Medical Centre Utrecht, Utrecht, The Netherlands.

Correspondence: Koos Korsten, Dept of Paediatric Infectious Diseases and Immunology, Wilhelmina Children's Hospital University Medical Centre Utrecht, PO Box 85090, 3508 AB, Utrecht, The Netherlands. Internal mail no. KE 04.133.1. E-mail: k.korstendumcutrecht.nl

\section{ABSTRACT}

Background: Because diagnosing asthma in school-aged children is challenging, a variety of proxies for asthma are used in clinical practice and research settings as indicators of this disease. We aimed to provide insight into the agreement between various asthma indicators based on parental report, medical diagnosis and spirometry.

Methods: Children from the WHISTLER birth cohort performed spirometry and were followed up with parental ISAAC (International Study of Asthma and Allergies in Childhood) questionnaires about asthma at 5 and 8 years of age. Medical data were extracted from primary care records. We compared 15 asthma indicators based on parental report, medical diagnosis and spirometry using positive agreement, $\kappa$ statistics and latent class cluster analysis.

Results: At 5 years of age, 1007 children completed a study visit, while 803 children visited at 8 years of age. Depending on the indicator, the responder and child's age, the asthma prevalence ranged from $0.2 \%$ to $26.6 \%$. Cluster analysis revealed classes related to the presence of recent symptoms and a decreased lung function. Agreement between parents and doctors was generally low with $\kappa$ coefficients ranging from 0.07 (recent wheeze) to 0.52 (recent asthma medication). Additionally, parental report showed to be sensitive to recall bias over time.

Conclusions: Dependent on the asthma indicator, the responder and the age of the child, substantial differences in agreement were observed between commonly used indicators associated with asthmatic disease in school-aged children. Most agreement between parents and doctors was seen for objective and recent indicators such as the recent use of asthma medication. We advocate caution when literature with different asthma indicators is compared.

@ERSpublications

A variety of clinical definitions are used as indicators of asthma. There are substantial differences in agreement between parents, doctors and lung function. Caution is needed when literature with different asthma indicators is compared. https://bit.ly/2VxDH8p

Cite this article as: Korsten $\mathrm{K}$, Naaktgeboren CA, Bont LJ, et al. Defining asthma in children: how well do parents, doctors and spirometry agree? ERJ Open Res 2020; 6: 00348-2019 [https://doi.org/ 10.1183/23120541.00348-2019].

This article has supplementary material available from openres.ersjournals.com

Received: 12 Dec 2019 | Accepted after revision: 26 June 2020

Copyright $\odot$ ERS 2020. This article is open access and distributed under the terms of the Creative Commons Attribution Non-Commercial Licence 4.0. 


\section{Introduction}

Worldwide, over 358 million people are estimated to have asthma, making this disease one of the most common chronic diseases [1]. The prevalence of asthma based on national registries ranges from $1.7 \%$ to $13.5 \%$ in western countries [1-3]. While some variation can be explained by differences in region and study population, the use of proxies for medical diagnoses also likely contributes to differences in asthma prevalence [4]. There are a variety of proxies for asthma, as shown in a systematic review of 122 published articles, which found 60 different indicators [4]. Moreover, it is increasingly acknowledged that asthma is an umbrella term that includes several phenotypes. Differences between indicators of asthma can therefore also reflect different phenotypes of this disease.

While it is still largely unknown whether these indicators reflect a similar condition and whether it is justifiable to compare results from studies using different indicators, we hypothesise that much of the variability in the prevalence of asthma is a result of how it is defined and measured. Knowing which asthma indicators are related and which ones differ is important to facilitate a better comparison of published literature as well as aid to the selection of appropriate end-points for defining asthma in future studies. Moreover, knowledge about the agreement between different indicators is not only useful for research, but is also required to ask the right questions to parents in order to obtain the most meaningful information in clinical practice. In this study we aim to investigate the agreement between indicators that are commonly used in literature to define asthmatic disease based on parental report to determine how they relate to indicators based on medical diagnosis and lung function in children aged 5 and 8 years old.

\section{Methods \\ Study population}

This study was performed as part of the WHeezing and Illnesses STudy LEidsche Rijn (WHISTLER), an ongoing prospective birth-cohort study on determinants of wheezing illnesses. Healthy term born infants born between December 2001 and December 2012 living in the Leidsche Rijn district of Utrecht, the Netherlands were enrolled within 2 months after birth. Exclusion criteria at baseline were gestational age $<36$ weeks, major congenital abnormalities and neonatal respiratory disease. The study design and rationale of WHISTLER are described in detail elsewhere [5]. The WHISTLER project was approved by the medical ethical committee of the University Medical Centre Utrecht, the Netherlands. Written informed consent was obtained from the parents.

\section{Data collection}

At the age of 5 years all children that were initially enrolled in the birth cohort were invited for a study visit during which lung function was assessed using spirometry. A maximum of 1000 participants were recruited for follow-up at 5 years of age. Spirometry was performed using a calibrated spirometer (ZAN 100 spirometer, nSpire, Colorado, USA) and all children withheld their rescue medication for at least $12 \mathrm{~h}$ beforehand [5] If the child had suffered from a respiratory tract infection in the last 2 weeks, the test was postponed. Maximal flow-volume curves were measured according to the European Respiratory Society/ American Thoracic Society standards [6]. The largest forced expiratory volume in $0.5 \mathrm{~s}\left(\mathrm{FEV}_{0.5}\right), 1 \mathrm{~s}$ $\left(\mathrm{FEV}_{1}\right)$ and forced vital capacity (FVC) were selected from three correctly performed assessments. Additionally, standardised ISAAC (International Study of Asthma and Allergies in Childhood) questionnaires about atopic diseases and asthmatic symptoms were filled out by the parents during these study visits irrespective of a successful lung function test. Medical data about doctor's visits and the use of medication by these children were extracted from the general practitioners' electronic medical database using the International Classification of Primary Care (ICPC) [7] and the Anatomical Therapeutical Chemical (ATC J01) coding systems. Children that completed the 5-year follow-up were subsequently invited for a similar second study visit at the age of 8 years.

\section{Indicators of asthma}

Commonly used proxies of asthmatic disease were selected for this study based on literature and availability in WHISTLER [4]. In this paper, we will refer to these proxies as "indicators of asthma" because of their presumed association with the risk of asthmatic disease. Clinical indicators based on either parental opinion or medical diagnosis included; current asthma, ever asthma, current wheeze, ever wheeze and the current use of asthma medication. The time constraint for "current" was within the past 12 months while "ever" was defined as a history of asthma/wheeze at some moment in their life. Parent-reported indicators were based on the ISAAC questionnaire, whereas their equivalents from medical diagnosis were based on ICPC and ATC codes. Indicators of a lung function deficit $\left(\mathrm{FEV}_{0.5}\right.$, $\mathrm{FEV}_{1}, \mathrm{FVC}, \mathrm{FEV}_{0.5} / \mathrm{FVC}$ and $\mathrm{FEV}_{1} / \mathrm{FVC}$ ) were dichotomised at the lower limit of normal (LLN), below the fifth percentile of predicted, using the Dutch normative values, which are corrected for age, length and sex [8]. The exact definitions of all indicators used in this article can be found in supplementary table S1. 


\section{Statistical analysis}

First, we analysed the cross-sectional agreement between different indicators at age 5 and 8 years. We determined agreement between indicators in three ways to provide a balanced view about their relations. Positive agreement was calculated to provide unilateral agreement between two variables. Cohen's $\kappa$ coefficients were calculated to determine bilateral agreement. Additionally, we performed latent class cluster analysis at age 5 years to study the agreement between multiple indicators by estimating clusters or "classes" of indicators of asthma. While latent class analysis can be used for the purpose of defining phenotypes of disease, our aim of the analysis was specifically to determine agreement between the included indicators of asthma. Proportional class membership probabilities of the included indicators in the final latent class cluster model were obtained to measure this agreement. Indicators within the same latent class are homogeneous, whereas indicators in different latent classes are dissimilar from each other. Clustering of indicators was graphically displayed in a tri-plot and bar chart. Detailed information about latent class cluster analysis, model development and model selection can be found in the supplementary material (latent class cluster analysis).

Second, we analysed intra-subject longitudinal consistency between ages 5 and 8 years. Longitudinal agreement was analysed by estimating Cohen's $\kappa$ coefficients and persistency and development of new cases for the same indicator between age 5 and 8 . No imputation of missing data was performed. Latent class analysis was performed using Latent Gold version 5.1 (Statistical Innovations Inc.), while other analyses were performed in $\mathrm{R}$ version 3.5.1.

\section{Results}

Participants

Of the 2443 children who initially participated in WHISTLER, 1144 children at the age of 5 years, and 1127 at the age of 8 years had data available from at least one source (study visit and/or registry data) (figure 1). At age 5, 1007 children were invited for a study visit of whom 992 completed the questionnaire and 940 attended the clinic for spirometry. Of those that visited the clinic 39 refused spirometry, 32 were technically unable to correctly execute the procedures, and 72 results were not reproducible resulting in 792 correctly performed assessments. At age 8,803 children were invited for a study visit of whom 782 completed the questionnaire and 719 attended the clinic. Of those that visited the clinic 1 refused, 9 assessments were technically insufficient and 28 were not reproducible, resulting in 681 correctly performed assessments. Baseline characteristics of participants during various stages of the WHISTLER study are shown in table 1 and data availability is shown in figure 1.

\section{Prevalence}

The prevalence of the clinical indicators of asthmatic disease at the ages of 5 and 8 years as reported by parents or based on medical diagnosis ranged from $0.2 \%$ (medically diagnosed current wheeze at age 8 ) to $26.6 \%$ (parent-reported ever wheeze at age 5) (table 2). The incidence of medically diagnosed recent wheeze declined rapidly after the first years of life based on the ICPC database with incidences of $4.4 \%$, $2.2 \%, 1.2 \%$ and $1.2 \%$ in the first 4 years of life, respectively. Based on spirometry, the prevalence of a lung function deficit below the LLN ranged from $4.4 \%$ to $7.6 \%$ (table 3 ).

\section{Agreement at age 5 and 8}

Agreement between parents and doctors at age 5 is displayed in figures 2 and 3. Unilateral positive agreement showed a very poor agreement for recent wheeze (4\% agreement) but a good agreement of $75 \%$ for the recent use of asthma medication (figure 2). This was confirmed by $\kappa$ ranging from 0.07 (no agreement) for recent wheeze to 0.52 (moderate agreement) for asthma medication (figure 3). Most agreement between parents and doctors was seen for recent asthma and recent asthma medication use. The associations observed at age 5 years between recent asthma and recent asthma medication were confirmed at 8 years of age (figures S1 and S2).

Generally poor agreement was seen between lung function indicators and the clinical indicators as reported by parents at age 5 (figures 2 and 3). Although agreement was slightly better at age 8 , the $\kappa$ statistics indicated "fair" agreement at best (figures S1 and S2). Despite this low agreement, children with a clinical label of asthma did show a decreased lung function compared to those without an asthmatic label (table S2). However, most children still remained within the limits of normality.

\section{Cluster analysis at age 5}

A four-class model best fitted the underlying agreement in the data in the latent class cluster analysis. Details about the model development, selection process and the individual class membership probabilities can be found in the supplemental material (latent class cluster analysis, figure S3). Clustering of indicators based on these probabilities was graphically displayed in the tri-plot shown in figure 4. Negative answers 


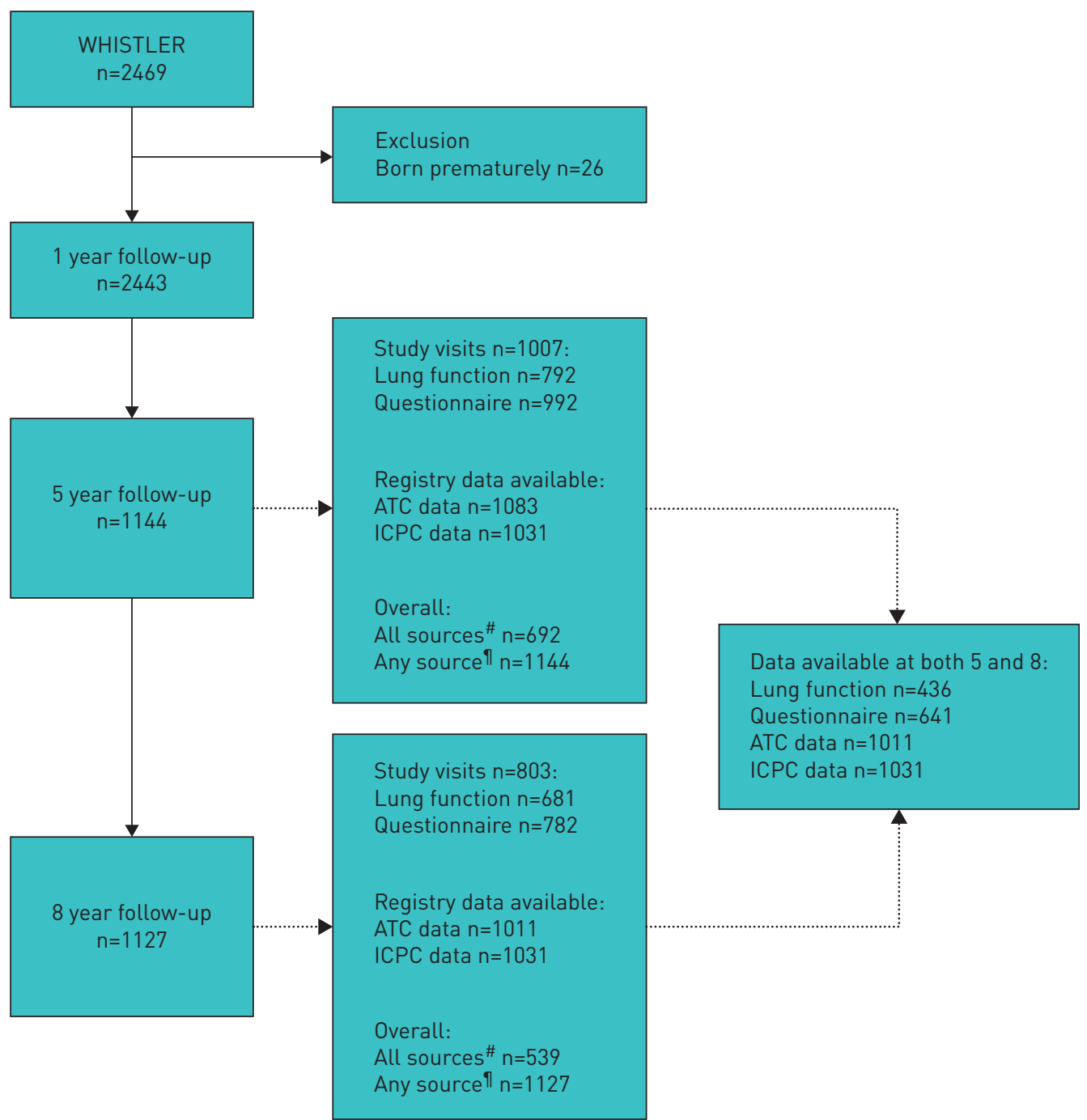

FIGURE 1 Flowchart. \#: Data available from all data sources (questionnaires, lung function assessment, Anatomical Therapeutical Chemical (ATC) and International Classification of Primary Care (ICPC) registries): १: data available from at least one data source.

to all of the included indicators (e.g. not having recent asthma) clustered together and were collectively labelled as cluster "no asthma", which comprised $80 \%$ of the participants. The second cluster consisted of indicators of recent asthmatic symptoms and included $9 \%$ of the participants. Cluster three included indicators based on a lung function deficit and included $6 \%$ of the participants. Lastly, some indicators did not have a clear predominance to be assigned to either of the clusters and remained in the middle of the plot. These included indicators of a history of symptoms and a diminished $\mathrm{FEV}_{0.5}$.

\section{Longitudinal agreement}

Based on parental report, indicators of a history of symptoms were most constant over time (54-58\% consistency) (table 4). However, nearly half of these "ever" diagnoses reported at age 5 were therefore not reported at age 8, indicating a substantial loss in the recollection of these past symptoms over time by parents. The indicator that showed most consistency for ongoing current symptoms was the presence of current asthma both based on parental opinion (41.2\% consistency) as well as based on medical diagnosis ( $25.0 \%$ consistency). Lung function was relatively constant over time as indicated by $20 \%$ to $45 \%$ consistency of these indicators.

\section{Discussion}

This study aimed to provide insight into the agreement of the wide variety of indicators of asthmatic disease used in clinical practice and research settings to define asthma in children. Considerable variance in agreement between responders as well as large variance in the prevalence was observed when common 
TABLE 1 Baseline characteristics

Total cohort $(n=2443)$

With 5-year follow-up ( $n=1007)$

With 8-year follow-up ( $\mathrm{n}=803$ )

Sex male
Age at follow-up in months median \pm sD
Birth weight $g$
wGA weeks+days
Breastfed
Siblings
Day care attendance
Pre-natal smoke exposure
Smoking parents lat least one)
Asthmatic mother
Asthmatic father
Allergic mother
Allergic father
High educational level mother
High educational level father

$1191 / 2443(49 \%)$
$3544 \pm 500$
$39+6$ ( \pm 9 days)
$1320 / 2439(54 \%)$
$1134 / 2443(46 \%)$
$2367 / 2440(97 \%)$
$318 / 2427(13 \%)$
$415 / 2008(21 \%)$
$184 / 2125(9 \%)$
$116 / 2019(6 \%)$
$802 / 2152(37 \%)$
$785 / 2040(39 \%)$
$1473 / 2105(70 \%)$
$1284 / 2002(64 \%)$

$485 / 1007$ (48\%)

$65 \pm 4.6$

$3552 \pm 498$

$39+6$ ( \pm 9 days)

$521 / 915(57 \%)$

421/916 (46\%)

$893 / 915(98 \%)$

$160 / 912(18 \%)$

$173 / 756(23 \%)$

$74 / 808(9 \%)$

$48 / 769(6 \%)$

$310 / 815(38 \%)$

$310 / 774(40 \%)$

$551 / 803(69 \%)$

$452 / 766(59 \%)$
$370 / 803(46 \%)$

$107 \pm 11.6$

$3561 \pm 481$

$39+6$ ( \pm 9 days)

$430 / 742(42 \%)$

$353 / 743(48 \%)$

$723 / 742(97 \%)$

$118 / 740(16 \%)$

$141 / 632(22 \%)$

$62 / 675(9 \%)$

$37 / 644(6 \%)$

$257 / 681(38 \%)$

$262 / 650(40 \%)$

$453 / 671(68 \%)$

$381 / 640(60 \%)$

Data are presented as $\mathrm{n} /$ total $(\%)$ or mean \pm SD, unless otherwise stated. wGA: weeks gestational age. ${ }^{\text {* }}$ : At least 1 month in the first year of life;

१: either maternal smoking or exposure of the mother to smoke; ${ }^{+}$: reported hay fever or allergy for house-dust mite, animals or food:

§: educational level higher than secondary school.

indicators of childhood asthma were compared. Our analysis revealed distinct clusters of more comparable indicators, namely those that indicated the presence of current symptoms and indicators of a lung function deficit. Additionally, we observed substantial problems in the recollection by parents of a history of symptoms.

Disagreement between parents and doctors in reporting asthmatic disease has been observed before [9-14]. Parents report higher rates of a history of wheeze and asthma compared to doctors [9, 10, 14]. We observed that the incidence of medically attended wheeze decreases significantly after the first years of life and is nearly absent at school age. However, these symptoms still persist based on parental report. Based on parental report, the yearly number of episodes of wheeze in children with persistent wheeze was comparable at age 5 and 8 years. We therefore hypothesise that the inconsistency between parental and doctor report could be the result of parents getting familiar with their child's symptoms and do no longer seek medical attention. Parental report of a history of (doctor-diagnosed) asthma has been suggested as a stable indicator of childhood asthma over time and reflected most agreement with the prevalence obtained by medical diagnosis $[13,15,16]$. Although we also confirm this agreement, we do show that there is significant recall bias based on parental report for a history of asthmatic disease. This recall bias combined with the poor agreement we observed with the presence of current symptoms can in our opinion strongly diminish the clinical value of using these lifetime indicators. Moreover, these "ever" indicators showed less probability to fall into one of the classes in our analysis, suggesting that they are more representative of children in which symptoms are in remission or resolved. Similar to our findings, a higher agreement between parents and doctors was seen for recent objective indicators such as the recent use of asthma

TABLE 2 Prevalence of indicators at age 5 and 8 years

\begin{tabular}{|c|c|c|c|c|}
\hline Indicator ${ }^{\#}$ & \multicolumn{2}{|c|}{ Age 5 years } & \multicolumn{2}{|c|}{ Age 8 years } \\
\hline Asthma (ever) & $68 / 974(7.0 \%)$ & $75 / 1031(7.3 \%)$ & $71 / 772$ (9.2\%) & $98 / 1031(9.4 \%)$ \\
\hline Current wheeze & $73 / 976(7.5 \%)$ & $4 / 1031(0.4 \%)$ & $43 / 776$ (5.5\%) & $2 / 962(0.2 \%)$ \\
\hline Wheeze (ever) & $260 / 978(26.6 \%)$ & $50 / 1031(4.8 \%)$ & 154/777 (19.8\%) & $55 / 1031(4.8 \%)$ \\
\hline \multicolumn{5}{|c|}{$\begin{array}{l}\mathrm{n} \text { : cases with the indicator. Denominators may change due to differences in missing values, based on the source of report and age of the } \\
\text { child. \#: see table S1 for the exact definitions; П: Questions about current asthma and current asthma medication were rephrased during } \\
\text { follow-up resulting in only a minority of participants at age } 8 \text { years who answered to the same question as compared to age } 5 \text { years. }\end{array}$} \\
\hline
\end{tabular}




\section{TABLE 3 Prevalence of lung function deficit at age 5 and 8 years}

\begin{tabular}{|c|c|c|}
\hline Indicator" & $\begin{array}{c}\text { Age } 5 \text { years } \\
\text { n/total }(\%)\end{array}$ & $\begin{array}{c}\text { Age } 8 \text { years } \\
\text { n/total }(\%)\end{array}$ \\
\hline FEV $_{0.5}(<L L N)$ & $47 / 777$ (6.0\%) & $44 / 581(7.6 \%)$ \\
\hline FEV $_{1}(<L L N)$ & $53 / 792(6.7 \%)$ & $46 / 676(6.8 \%)$ \\
\hline FVC $(<L L N)$ & $57 / 792(7.2 \%)$ & $51 / 676(7.5 \%)$ \\
\hline $\mathrm{FEV}_{0.5} / \mathrm{FVC}(<\mathrm{LLN})$ & $47 / 776(6.1 \%)$ & $35 / 581(6.0 \%)$ \\
\hline $\mathrm{FEV}_{1} /$ FVC (<LLN) & $49 / 791(6.2 \%)$ & $30 / 675(4.4 \%)$ \\
\hline
\end{tabular}

$\mathrm{n}$ : cases with the indicator; LLN: lower limit of normal or below the 5th percentile of predicted; FEV: forced expiratory volume in either $0.5\left(\mathrm{FEV}_{0.5}\right)$ or $1 \mathrm{~s}\left(\mathrm{FEV}_{1}\right)$; FVC: forced vital capacity. ${ }^{\text {* }}$ : see table $\mathrm{S} 1$ for exact definitions.

medication [11, 12]. Positive agreement for recent use of respiratory medication in these studies ranged from $64 \%$ [11] to $87 \%$ [12], which is comparable to the $75 \%-78 \%$ at age 5 and 8 years that we observed.

We observed poor agreement between lung function and clinical symptoms. Although counterintuitive, this mismatch between a clinical diagnosis of asthma and lung function tests has been reported before [17], as well as disagreement between current symptoms and lung function as indicators of asthma severity [18, 19]. Although we observed a decreased lung function in children with an asthmatic label, the majority of asthmatic children still had a lung function within the boundaries of normality. Cut-off values such as the LLN are perhaps too strict in children which also matches with the observation that the commonly used cut-off values for $\mathrm{FEV}_{1}$ and the $\mathrm{FEV}_{1} / \mathrm{FVC}$ ratio do not match well with clinical asthma in children [17].

Strengths of our study are the cohort size and the availability of different sources of asthma-related data at both the ages of 5 and 8 . This allowed for comparing a variety of commonly used indicators based on parent report, medical diagnosis and spirometry. Repeated measurements at age 5 and 8 allowed us to determine the temporal relations of various indicators during this crucial period of development. We used multiple statistical methods to analyse agreement which showed uniform results.

Limitations have to be discussed as well. First, although coverage of primary care visits in this database is very complete, the use the registration codes for obtaining a medical diagnosis could have attributed to a lower incidence of medical diagnoses compared to what was reported by parents because registries can be less sensitive for mild symptoms [20]. One could imagine that an episode of wheeze, if triggered by a respiratory infection, is coded as respiratory infection rather than wheeze. Free text analysis of the clinical records would have been more sensitive but was unfortunately unavailable in this study. Second, the

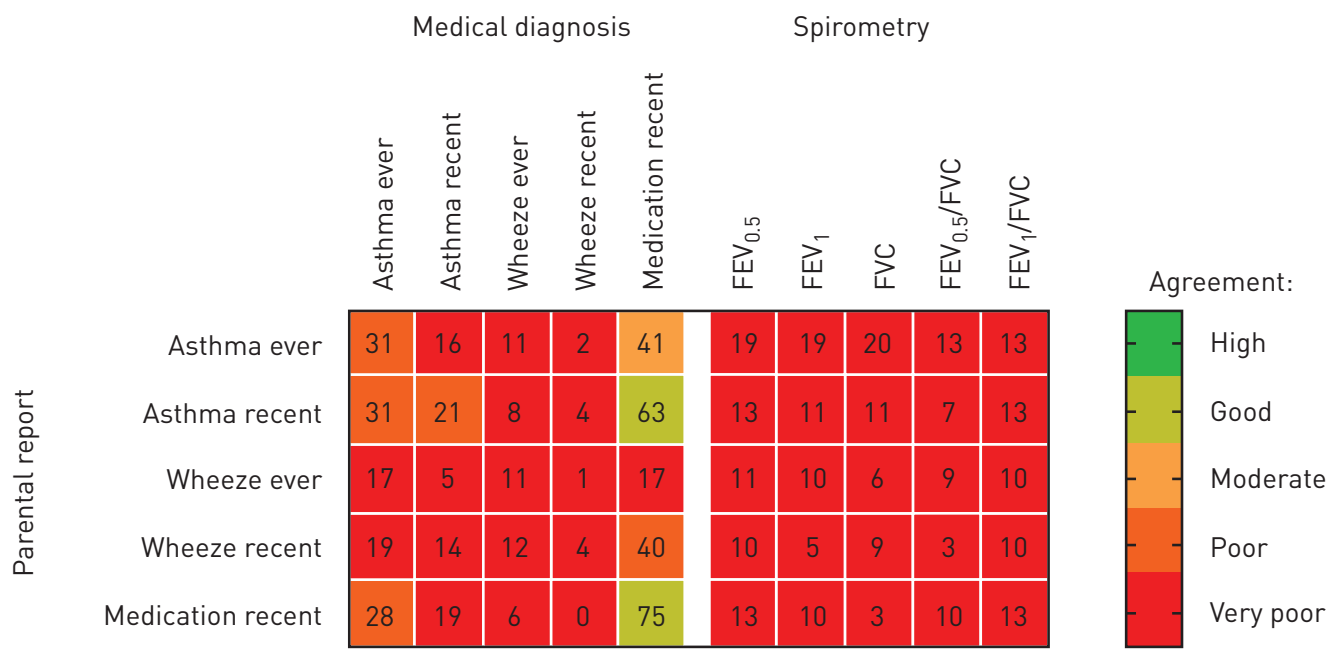

FIGURE 2 Agreement at age 5 years (positive agreement). Positive agreement is shown unilaterally for the horizontal indicator compared to the vertical indicator. For example, a parental report of recent asthma medication is in $75 \%$ of the cases confirmed in the doctor's registry. Lung function deficit is dichotomised based on the lower limits of normal $\left(<5\right.$ th percentile) $\mathrm{FEV}_{0.5}$ : forced expiratory volume in $0.5 \mathrm{~s} ; \mathrm{FEV}_{1}$ : forced expiratory volume in $1 \mathrm{~s}$; FVC: forced vital capacity. 


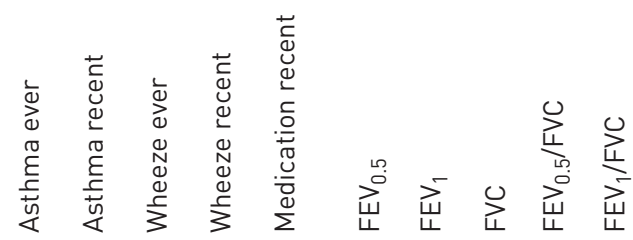

Asthma ever

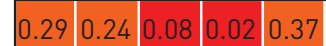

$\frac{1}{0}$
$\frac{0}{0}$
$\frac{0}{\pi}$
$\frac{\pi}{c}$
$\frac{0}{0}$
$\frac{0}{0}$

\section{Asthma recent}

Wheeze ever

Wheeze recent

Medication recent

\section{\begin{tabular}{ll|l|l|l|l|l|l|l}
0.27 & 0.32 & 0.03 & 0.06 & 0.56
\end{tabular}}

\begin{tabular}{l|l|l|l|l|l|l|l|l}
0.20 & 0.07 & 0.12 & 0.02 & 0.19
\end{tabular}

\begin{tabular}{|c|c|c|c|c|}
\hline 0.16 & 0.22 & 0.09 & 0.07 & 0.37 \\
\hline 0.19 & 0.27 & 0 & 0 & 0.52 \\
\hline
\end{tabular}

\section{Agreement:}

Almost perfect

Substantial

Moderate

Fair

None-slight

No

FIGURE 3 Agreement at age 5 years $(\kappa)$. Cohen's $\kappa$ show bilateral agreement between the indicators. For example, the agreement between recent medication use for parents and doctors is 0.52 indicating moderate agreement. Lung function deficit is dichotomised based on the lower limits of normal $(<5$ th percentile). $\mathrm{FEV}_{0.5}$ : forced expiratory volume in $0.5 \mathrm{~s} ; \mathrm{FEV}_{1}$ : forced expiratory volume in $1 \mathrm{~s}$; FVC: forced vital capacity.

WHISTLER cohort was over-represented with families with a high socioeconomic status (SES) compared to the district average. Although evidence is conflicting, more studies point towards an increased burden of asthma in children with a low-SES [21]. Asthma incidence could therefore be underestimated in our study.

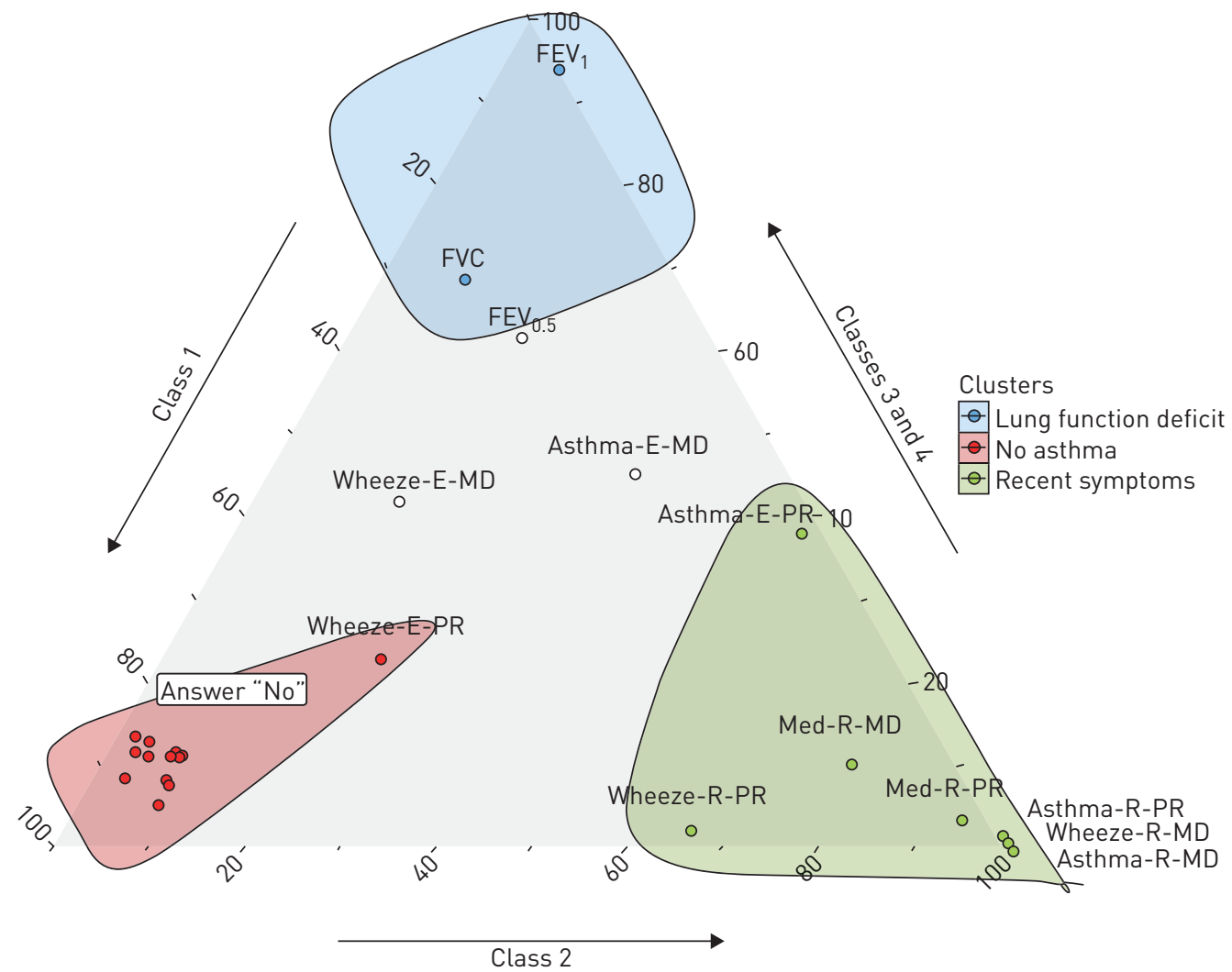

FIGURE 4 Tri-plot of class membership probabilities and clustering of indicators at age 5 years. The tri-plot indicates the class membership probabilities and clustering by arranging all proportional class membership probabilities of a variable as one data point in a triangular plane in which each point of the triangle represents a class. Probabilities for classes 3 and 4 are summed together in the top of the triangle to form the tri-plot. Variables are coloured and encircled based on their highest probability for one of the four classes. If variables did not have a clear predominance $\mid<50 \%$ probability to be assigned to either one of the classes), they were not coloured. Cluster names are based on the majority of indicators in that circle. PR: parent-reported; MD: medical diagnosis; E: ever; R: recent; med: medication; $\mathrm{FEV}_{0.5}$ : forced expiratory volume in $0.5 \mathrm{~s} ; \mathrm{FEV}_{1}$ : forced expiratory volume in $1 \mathrm{~s}$; FVC: forced vital capacity. 
TABLE 4 Longitudinal consistency between the age of 5 and 8 years old

\begin{tabular}{|c|c|c|c|c|c|}
\hline \multirow[b]{2}{*}{ Indicator \# } & \multirow[b]{2}{*}{$\begin{array}{l}\text { Age } 5 \text { years } \\
\text { prevalence } \\
\text { n/total }(\%)\end{array}$} & \multirow[b]{2}{*}{$\begin{array}{l}\text { Age } 8 \text { years } \\
\text { prevalence } \\
\text { n/total }(\%)\end{array}$} & \multicolumn{3}{|c|}{ Consistency and agreement at age 8 years } \\
\hline & & & $\begin{array}{l}\text { Persistent cases } \mathrm{n} / \text { total with } \\
\text { symptoms at age } 5 \text { years (\%) }\end{array}$ & $\begin{array}{c}\text { New cases } \mathrm{n} / \text { total cases } \\
\text { at age } 8 \text { years }(\%)\end{array}$ & Cohen's $k$ \\
\hline \multicolumn{6}{|l|}{ Parent-reported } \\
\hline Current wheeze & $47 / 625(7.5 \%)$ & $29 / 625(4.6 \%)$ & $12 / 47(25.5 \%)$ & $17 / 29(58.6 \%)$ & 0.27 \\
\hline "Ever" wheeze & $168 / 626(26.8 \%)$ & $118 / 626(18.8 \%)$ & $91 / 168(54.2 \%)$ & $27 / 118(22.3 \%)$ & 0.53 \\
\hline Current asthma" & $17 / 273(6.2 \%)$ & $10 / 273(3.7 \%)$ & $7 / 17(41.2 \%)$ & $3 / 10(30.0 \%)$ & 0.50 \\
\hline "Ever" asthma & $41 / 621(6.6 \%)$ & $50 / 621(8.1 \%)$ & $29 / 41(58.0 \%)$ & $21 / 50(42.0 \%)$ & 0.61 \\
\hline Current asthma medication & $12 / 276(4.3 \%)$ & $8 / 276(2.9 \%)$ & $3 / 12(25.0 \%)$ & $5 / 8(62.5 \%)$ & 0.27 \\
\hline \multicolumn{6}{|l|}{ Medical diagnosis } \\
\hline Current wheeze & $4 / 962(0.4 \%)$ & $2 / 962(0.2 \%)$ & $0 / 4(0 \%)$ & $2 / 2(100 \%)$ & 0 \\
\hline "Ever" wheeze & $50 / 1031(4.8 \%)$ & $55 / 1031(5.3 \%)$ & $50 / 50(100 \%)$ & $5 / 55(9.1 \%)$ & 0.95 \\
\hline Current asthma & $16 / 962(1.7 \%)$ & $19 / 962(2.0 \%)$ & $4 / 16(25.0 \%)$ & $15 / 19(78.9 \%)$ & 0.21 \\
\hline "Ever" asthma & $75 / 1031(7.3 \%)$ & $98 / 1031(9.5 \%)$ & $75 / 75(100 \%)$ & $23 / 98(23.5 \%)$ & 0.86 \\
\hline Current asthma medication & $68 / 1011(6.7 \%)$ & $28 / 1011(2.8 \%)$ & $13 / 68(19.1 \%)$ & $15 / 28(53.6 \%)$ & 0.24 \\
\hline \multicolumn{6}{|l|}{ Lung function (<LLN) } \\
\hline $\mathrm{FEV}_{0.5}$ & $20 / 357(5.6 \%)$ & $29 / 357(8.1 \%)$ & $9 / 20$ (45.0\%) & $20 / 29(69.0 \%)$ & 0.32 \\
\hline $\mathrm{FEV}_{1}$ & $28 / 432(6.5 \%)$ & $32 / 432(7.4 \%)$ & $12 / 28(42.9 \%)$ & $20 / 32(62.5 \%)$ & 0.36 \\
\hline FVC & $30 / 432(6.9 \%)$ & $30 / 432(6.9 \%)$ & $8 / 30(26.7 \%)$ & $22 / 30(73.3 \%)$ & 0.21 \\
\hline $\mathrm{FEV}_{0.5} / \mathrm{FVC}$ & $20 / 357(5.6 \%)$ & $22 / 357(6.2 \%)$ & $4 / 20(20.0 \%)$ & $18 / 22(81.8 \%)$ & 0.14 \\
\hline $\mathrm{FEV}_{1} / \mathrm{FVC}$ & $25 / 431(5.8 \%)$ & $22 / 431(5.1 \%)$ & $8 / 25(32.0 \%)$ & $14 / 22(63.6 \%)$ & 0.30 \\
\hline \multicolumn{6}{|c|}{ 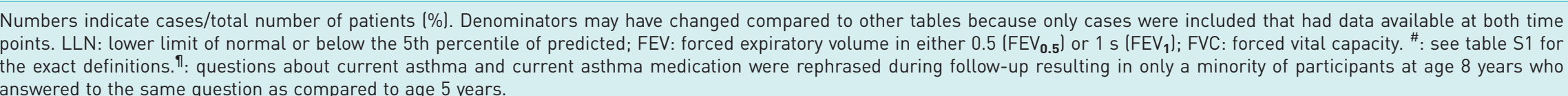 } \\
\hline
\end{tabular}


As primary care is freely accessible in the Netherlands, we do not expect that SES disproportionally affected the medically diagnosed indicators compared to the parent-reported indicators. Therefore, we believe that it is unlikely that SES affected the underlying agreement between the indicators when assumed that all are evenly underestimated. Third, only approximately $40 \%$ of the initial study population of WHISTLER participated in follow-up at age 5 and 33\% completed follow-up at the age of 8 years. Although planned, this selective follow-up could introduce selection bias. However, as baseline characteristics of participants in various stages of follow-up did not show major differences, we believe that the risk of having selected a different subpopulation of our cohort for follow-up is small. Fourth, not all sources of reporting were available for all participants. Data were not so much missing but rather "absent" in the presence of more data from an alternative source such as a medical record. We were therefore unable to compare all data from different sources of information for all individual participants. We chose not to impute missing data if no direct comparison could be made as this would imply that we had to impute complete study visits when only medical registry data was available. Also, with fewer data available at age 8 , the results of the analyses at the age of 5 years are more robust. Fifth, we did not to evaluate reversibility or performed challenge tests during spirometry in our cohort of otherwise healthy children which may have attributed to the low agreement we observed compared to the clinical end-points. However, this disagreement has also been reported in a study that did compare between reported symptoms and results from various lung function tests [17]. Last, we describe agreement and differences between indicators of asthmatic disease but did not investigate the clinical implications of having such a label. For clinical relevance, it would be interesting to know which of the indicators are more correlated with a diminished quality of life or require more medical care. This knowledge could aid in the selection of end-points that are not only agreed upon, but are also clinically relevant.

\section{Conclusion}

Dependent on the indicator, the responder and the age of the child, we found substantial differences in agreement and prevalence between various commonly used indicators associated with asthmatic disease in school-aged children from an unselected birth cohort. These data advocate caution when literature with different asthma indicators is compared. Based on these results, we advise the use recent and objective indicators, such as a recent asthma diagnosis and the recent use of asthma medication because they displayed the highest agreement between parents and doctors with the lowest risk of recall bias over time.

Acknowledgements: We thank Lidian Izeboud and Rolien Bekkema (Dept of Paediatric Pulmonology, Wilhelmina Children's Hospital, Utrecht, the Netherlands) for helping us performing the spirometry assessment in the children that visited the clinic. We would like to thank all parents and children who willingly cooperated in this study.

Conflict of interest: K. Korsten has nothing to disclose. C.A. Naaktgeboren has nothing to disclose. L.J. Bont is the founding chairman of the ReSViNET Foundation. L.J. Bont has regular interaction with pharmaceutical and other industrial partners. He has not received personal fees or other personal benefits. UMCU has received major funding (greater than $€ 100000$ per industrial partner) for investigator-initiated studies from AbbVie, MedImmune, Janssen, the Bill and Melinda Gates Foundation, Nutricia (Danone) and MeMed Diagnostics. UMCU has received major cash or in-kind funding as part of the public-private partnership IMI-funded RESCEU project from GSK, Novavax, Janssen, AstraZeneca, Pfizer and Sanofi. UMCU has received major funding by Julius Clinical for participating in the INFORM study sponsored by MedImmune. UMCU has received minor funding for participation in trials by Regeneron and Janssen from 2015-2017 (total annual estimate less than €20000). UMCU received minor funding for consultation and invited lectures by AbbVie, MedImmune, Ablynx, Bavaria Nordic, MabXience, Novavax, Pfizer, Janssen (total annual estimate less than €20000). C.K. van der Ent reports grants from GSK, Nutricia, TEVA, Gilead, Vertex, ProQR, Proteostasis and Galapagos NV, outside the submitted work. M.L.A. de Hoog has nothing to disclose.

Support statement: This study was supported by ZonMw grant 2001-1-1322. Funding information for this article has been deposited with the Crossref Funder Registry.

\section{References}

1 Vos T, Allen C, Arora M, et al. Global, regional, and national incidence, prevalence, and years lived with disability for 310 diseases and injuries, 1990-2015: a systematic analysis for the Global Burden of Disease Study 2015. Lancet 2016; 388: 1545-1602.

2 Akinbami LJ, Moorman JE, Liu X. Asthma prevalence, health care use, and mortality: United States, 2005-2009. Natl Health Stat Report 2011: 1-14.

3 Uphoff EP, Bird PK, Antó JM, et al. Variations in the prevalence of childhood asthma and wheeze in MeDALL cohorts in Europe. ERJ Open Res 2017; 3: 00150-2016.

4 Van Wonderen KE, Van Der Mark LB, Mohrs J, et al. Different definitions in childhood asthma: how dependable is the dependent variable? Eur Respir J 2010; 36: 48-56.

5 Katier N, Uiterwaal CS, de Jong BM, et al. The Wheezing Illnesses Study Leidsche Rijn (WHISTLER): rationale and design. Eur J Epidemiol 2004; 19: 895-903.

6 Miller MR, Hankinson J, Brusasco V, et al. Standardisation of spirometry. Eur Respir J 2005; 26: 319-338.

7 Verbeke M, Schrans D, Deroose S, et al. The International Classification of Primary Care (ICPC-2): an essential tool in the EPR of the GP. Stud Health Technol Inform 2006; 124: 809-814. 
8 Koopman M, Zanen P, Kruitwagen CL, et al. Reference values for paediatric pulmonary function testing: the Utrecht dataset. Respir Med 2011; 105: 15-23.

9 Miller JE. Predictors of asthma in young children: does reporting source affect our conclusions? Am J Epidemiol 2001; 154: 245-250.

10 Mohangoo AD, de Koning HJ, Hafkamp-de Groen E, et al. A comparison of parent-reported wheezing or shortness of breath among infants as assessed by questionnaire and physician-interview: the Generation R study. Pediatr Pulmonol 2010; 45: 500-507.

11 Greenlee RT, Chyou PH, Kieke A, et al. Prevalence of asthma in a general population cohort of farm children: comparison of estimates based on parental report and medical record review. J Agromedicine 2008; 13: 225-231.

12 Koster ES, Wijga AH, Raaijmakers JA, et al. High agreement between parental reported inhaled corticosteroid use and pharmacy prescription data. Pharmacoepidemiol Drug Saf 2010; 19: 1199-1203.

13 Canova C, Harris JM, Mills P, et al. Epidemiological measures of childhood asthma: cross-sectional and longitudinal consistency. Respir Med 2012; 106: 1226-1235.

14 Lowe L, Murray CS, Martin L, et al. Reported versus confirmed wheeze and lung function in early life. Arch Dis Child 2004; 89: 540-543.

15 Cornish RP, Henderson J, Boyd AW, et al. Validating childhood asthma in an epidemiological study using linked electronic patient records. BMJ Open 2014; 4: e005345.

16 de Marco R, Cerveri I, Bugiani M, et al. An undetected burden of asthma in Italy: the relationship between clinical and epidemiological diagnosis of asthma. Eur Respir J 1998; 11: 599-605.

17 Murray C, Foden P, Lowe L, et al. Diagnosis of asthma in symptomatic children based on measures of lung function: an analysis of data from a population-based birth cohort study. Lancet Child Adolesc Health 2017; 1: $114-123$.

18 Hallas HW, Chawes BL, Rasmussen MA, et al. Airway obstruction and bronchial reactivity from age 1 month until 13 years in children with asthma: a prospective birth cohort study. PLoS Med 2019; 16: e1002722.

19 Schifano ED, Hollenbach JP, Cloutier MM. Mismatch between asthma symptoms and spirometry: implications for managing asthma in children. J Pediatr 2014; 165: 997-1002.

20 Quan H, Li B, Saunders LD, et al. Assessing validity of ICD-9-CM and ICD-10 administrative data in recording clinical conditions in a unique dually coded database. Health Serv Res 2008; 43: 1424-1441.

21 Kozyrskyj AL, Kendall GE, Jacoby P, et al. Association between socioeconomic status and the development of asthma: analyses of income trajectories. Am J Public Health 2010; 100: 540-546. 